\title{
Tumor-Infiltrating Lymphocytes in Wilms Tumor
}

\begin{abstract}
Purpose: T-lymphocytes-infiltrating tumors (TILs) are white blood cells (CD3+) found within the tumor and are thought to indicate a T-cell-mediated specific immune response. The purpose was to evaluate the presence and the subtypes of TILs in Wilms tumor (WT) specimens. Materials and Methods: A prospective study was conducted, and consecutive cases of WT registered and treated at our center were included in the study. The resected tumor was processed by taking multiple sections from the tumor and the peritumoral area. The sections were then processed for evaluating TILs and their subtypes (CD4 + and CD8+). TILs were assessed as a percentage of the total mononuclear cell infiltration in both these areas in all specimens. Results: Twenty-four consecutive specimens of WT were studied. The mean TILs (CD3+) counts was significantly higher $(P=0.001)$ in the peritumoral area $(22.64 \pm 1.42$; range $20.2 \%-25 \%)$ as compared to the tumor $(21.08 \pm 2.42$; range $14.6 \%-23.1 \%)$. The mean T-Helper (CD4+) counts was also significantly higher $(P<0.001)$ in the peritumoral area $(13.04 \pm 1.79$; range $10.5 \%-16.5 \%)$ than in the tumor $(7.30 \pm 1.81$; range $4.2 \%-10.1 \%)$. The mean cytolytic T-lymphocytes (CTLs-CD8+) counts in peritumoral area were $6.64 \pm 1.09$ (range 4.2\%-9.2\%), while in the tumor, it was $11.96 \pm 3.09$ (range $3.6 \%-16.4 \%$ ). Two patients died on follow-up due to recurrence. These patients showed a markedly lower CD8+ cell count and higher $\mathrm{CD} 4+/ \mathrm{CD} 8+$ ratio in the tumor. Conclusion: T-cells infiltration takes place in WT, and most of the patients demonstrate a higher concentration of CTL (CD8+) in the tumor as compared to the peritumoral area.
\end{abstract}

Keywords: Immunosurveillance, tumor-infiltrating lymphocytes, Wilms tumor

\section{Introduction}

The immune surveillance emphasizes a reciprocal interaction between the incipient tumor and the host immune system. T-cells form a vital part of this immune system. Tumor-infiltrating lymphocytes (TILs) are defined as white blood cells that have left the bloodstream and migrated into a tumor. TILs consist of lymphocytes, mainly T-cells and minor populations of natural killer cells or B-cells. TILs may represent an active immune response of the host, specifically directed to the tumor. ${ }^{[1]}$ Immune cells, such as CD8+ T-cells, can naturally remove cancer cells, which implies that certain subtypes specifically recognize cancer cells by specific interactions with the T-cell receptor and tumor-associated peptides. These T-cell subtypes may contribute significantly to the efficacy of anti-cancer immunotherapy, including immune checkpoint blockades. ${ }^{[2]}$

Several attempts have been made to evaluate the infiltration and thus the

This is an open access journal, and articles are distributed under the terms of the Creative Commons Attribution-NonCommercial-ShareAlike 4.0 License, which allows others to remix, tweak, and build upon the work non-commercially, as long as appropriate credit is given and the new creations are licensed under the identical terms.

For reprints contact: WKHLRPMedknow_reprints@wolterskluwer.com prognostic significance of TILs in human cancers such as breast cancer, ${ }^{[3,4]}$ ovarian cancer, ${ }^{[5]}$ colorectal cancer, ${ }^{[6]}$ hepatocellular carcinoma, ${ }^{[7]}$ lung cancer, ${ }^{[8,9]}$ renal cell carcinoma, ${ }^{[10]}$ melanoma, ${ }^{[11]}$ gastric cancer, ${ }^{[12]}$ neuroblastoma, ${ }^{[13]}$ and sarcomas. $^{[14]}$ Pronounced lymphocytic infiltration has shown to be a prognostic parameter for better survival. This study was undertaken to study the presence of TILs and their subtype distribution in Wilms tumor (WT) in relation to the outcome.

\section{Materials and Methods}

This was a prospective study which involved consecutive cases of WT registered and treated at the pediatric Surgery Solid Tumor Clinic of our Institute. Ethical clearance was obtained from the Institutional Ethics Committee. Specimens of all patients with WT, who were operated primarily or after chemotherapy, were immediately taken to the department of pathology, and gross examination was carried out. Multiple sections were taken from the central part of the tumor and peritumoral region.

How to cite this article: Yadav DK, Jain V, Dinda AK, Agarwala S. Tumor-infiltrating lymphocytes in Wilms tumor. Indian J Med Paediatr Oncol 2019;40:34-8.
Devendra Kumar

Yadav ${ }^{1}$, Vishesh Jain 1 , Amit Kumar Dinda², Sandeep Agarwala ${ }^{1}$

${ }^{1}$ Department of Pediatric Surgery, All India Institute of Medical Sciences, New Delhi, India, ${ }^{2}$ Department of Pathology, All India Institute of Medical Sciences,

New Delhi, India

Submitted: 12-May-2019

Revised: 06-Oct-2019

Accepted: 10-Nov-2019

Published: 24-Apr-2020

Address for correspondence: Dr. Sandeep Agarwala, Department of Pediatric Surgery, All India Institute of Medical Sciences, Teaching Block, New Delhi - 110 029, India.

E-mail: sandpagr@hotmail.com

Access this article online Website: www.ijmpo.org

DOI: 10.4103/ijmpo.ijmpo_115_19 Quick Response Code:

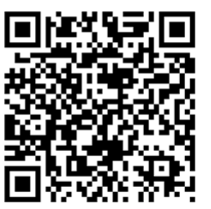




\section{Protocol for immunohistochemistry}

Tissue was fixed in $10 \%$ formalin and embedded in paraffin; 3-5- $\mu \mathrm{m}$ sections were obtained on poly-1 lysine coated slides. Slides were deparaffinized in xylene 2 times for $5 \mathrm{~min}$. Sections were rehydrated through graded alcohol. Sections were rinsed in phosphate-buffered solution (PBS) twice for $5 \mathrm{~min}$. Antigen retrieval: Slides were put in sodium citrate buffer ( $\mathrm{pH} 6.0,10 \mathrm{mM})$ and put in microwave for $10 \mathrm{~min}$ at $800 \mathrm{~W}$ for antigen retrieval. Serum blocking: slides were allowed to cool for $20 \mathrm{~min}$. Serum blocking was done to prevent nonspecific interactions of the antibodies. Tissue sections were incubated with primary antibodies (CD3+, CD4+, and $\mathrm{CD} 8+$ ) overnight at $4^{\circ} \mathrm{C}$. Primary antibodies were obtained from Dako, Denmark, and used at the appropriate dilution as provided in the company datasheet. Tissue sections were rinsed in PBS for 10 min. Peroxidase blocking: Peroxidase blocking was performed by incubating the sections in $3 \% \mathrm{H}_{2} \mathrm{O}_{2}$ in $\mathrm{PBS}$ for $10 \mathrm{~min}$. Sections were washed in PBS for $10 \mathrm{~min}$. Biotinylated secondary antibodies were added, and sections incubated for 15$30 \mathrm{~min}$ at room temperature. Rinse sections in PBS for 10 min. Streptavidin - peroxidase complex was added to the sections and incubated for $10 \mathrm{~min}$. Rinse sections in PBS for $10 \mathrm{~min}$. Development of chromogen: To visualize the antigen-antibody reaction, di-amine benzidine was used as chromogen with $0.3 \% \mathrm{H}_{2} \mathrm{O}_{2}$ as a substrate to visualize the antibody. The reaction was monitored under a compound microscope until suitable color development was obtained. The reaction was stopped by putting the slides in PBS. Slides were rinsed in distilled water and dried. They were counterstained with hematoxylin to visualize the nuclei.

Mononuclear cell infiltration was studied in both tumor and peritumor area. Ten fields were seen randomly. CD3+, CD4+, CD8+ cells infiltration was seen, and the percentage was calculated with respect to total mononuclear cells infiltration in both tumor and peritumor area within the renal parenchyma. The immunostained slides were imaged using an image analysis system. The image analysis system consisted of a research microscope $(B \times 50$; Olympus, Tokyo, Japan), 10-bit digital camera (Xilix Correco, Canada), image grabber card (F-64, Cerreco Corp, Quebec, Canada), and a personal computer (P-III; Digital Corp, California, USA). The image analysis software used was Optimal 5.2 (Optimas Corp, California, USA).

\section{Statistical analysis}

Statistical analysis was carried out using STATA 9.0 (College Station, TX, USA). Data were presented as mean \pm standard deviation or median (range) as appropriate. The difference in means/medians between tumor and peritumor groups was compared using $t$-test/ Wilcoxon rank-sum test.

\section{Results}

Twenty-two consecutive children with renal tumors were enrolled in this study. The patient characteristics are depicted in Table 1. Fifteen patients presented with an asymptomatic mass, three presented with abdominal pain and mass, two presented with mass and hematuria and two presented with pain, hematuria, and mass. Radiologically, inferior vena cava thrombsis was detected in two patients. Of the 22 patients with WT, 4 patients had stage 1 disease, 15 had stage 3 disease, 1 patient had stage 4 disease (bilateral lung metastasis), and two were of stage 5 disease. A total of 24 WT specimens were included in the present study (two bilateral tumors).

TILs in peritumoral and tumor tissues: The CD3+ counts [Table 2] in the peritumoral tissue ranged from $20.2 \%-25 \%$ with a mean of $22.64 \pm 1.42$ while that in the tumor tissue ranged from $14.6 \% 23.1 \%$ with a mean of $21.08 \pm 2.42(P=0.001)$. The CD4+ counts [Figure 1] in the peritumoral tissue ranged from $10.5 \%-16.5 \%$ with a mean of $13.04 \% \pm 1.79 \%$ while the range in the tumor tissue was $4.2 \%-10.1 \%$ with a mean of $7.30 \% \pm 1.81 \%(P<0.001)$. The CD8+ counts in the peritumoral tissue ranged from $4.2 \%$ to $9.2 \%$, with a mean of $6.64 \% \pm 1.09 \%$. The range in the tumor tissue was $3.6 \%-16.4 \%$, with a mean of $11.96 \% \pm 3.09 \%(P<0.001)$. The $\mathrm{CD} 4+/ \mathrm{CD} 8+$ ratio in the peritumoral tissue ranged from 1.37 to 2.92 , with a mean of $2.01 \pm 0.43$. The $\mathrm{CD} 4+/ \mathrm{CD} 8+$ ratio in the tumor tissue ranged from 0.21 to 2.625 , with a mean of $0.74 \pm 0.61(P<0.001)$.

Out of 22 patients with WT, two died during a mean follow-up of 100 months (80-118 months). Both the children died because of recurrence, which could not be

\begin{tabular}{|c|c|c|}
\hline \multicolumn{3}{|c|}{ Table 1: Patient demographics and survival } \\
\hline Parameter & & Patient $(n=22)$ \\
\hline Age (months & & $35.1 \pm 21.77$ \\
\hline Sex (male: fe & & 13:9 \\
\hline Laterality (ri & & $15: 5: 2$ \\
\hline Mean follow & ths) (range) & $100(80-118)$ \\
\hline 5-year OS an & & 90.9 \\
\hline \multicolumn{3}{|c|}{$\begin{array}{l}\text { SD - Standard deviation; OS - Overall survival; DFS - Disease-free } \\
\text { survival }\end{array}$} \\
\hline \multicolumn{3}{|c|}{$\begin{array}{l}\text { Table 2: Tumor-infiltrating lymphocytes as detected by } \\
\text { various markers in the tumoral and peritumoral area }\end{array}$} \\
\hline Marker & $\begin{array}{c}\text { Peritumoral } \\
\text { infiltration }(\%)\end{array}$ & $\begin{array}{c}\text { Tumoral } \\
\text { infiltration }(\%)\end{array}$ \\
\hline $\mathrm{CD} 3+$ & $22.64 \pm 1.42$ & $21.08 \pm 2.42$ \\
\hline CD4+ & $13.04 \pm 1.79$ & $7.03 \pm 1.81$ \\
\hline $\mathrm{CD} 8+$ & $6.64 \pm 1.09$ & $11.96 \pm 3.09$ \\
\hline $\mathrm{CD} 4+/ \mathrm{CD} 8+$ & $2.01 \pm 0.43$ & $0.74 \pm 0.61$ \\
\hline
\end{tabular}

The difference in the TILs in the tumoral and peritumoral area was statistically significant, with $P<0.001$.

TILs - T-lymphocytes-infiltrating tumors 
salvaged whereas all other patients had no recurrence and are disease-free, at last follow-up. These children, who had died, demonstrated a less degree of central tumor infiltration with TIL, with the total CD3+ count being $16 \%$ and $14.6 \%$ as compared to the mean of $21.72 \% \pm 1.54 \%$ [Table 1] for those who survived. The proportion of CD8+ infiltration into the central tumor tissue was much lower than those who survived (4\% and $3.6 \%$ with as compared to the mean of $12.83 \% \pm 1.9 \%$ for those who survived) [Figure 2]. The peritumoral infiltration by $\mathrm{CD} 3+$ cells and the subset of CD8+ cells were not different in those who died as compared to those who survived.

Seventeen children received preoperative chemotherapy, while the remaining 8 children were operated upfront. The degree of TIL infiltration in these two groups is mentioned in Table 3. There was no significant difference in TIL infiltration in these two subgroups.

\section{Discussion}

A dynamic microenvironment exists at the host-tumor interface where host immune cells interact directly with growing tumors. The microenvironment of a growing tumor represents the complex and dynamic interaction between an invading tumor and the inflammatory/ immune response. Tumor invasion through the basement membrane is required for metastasis and is predicted

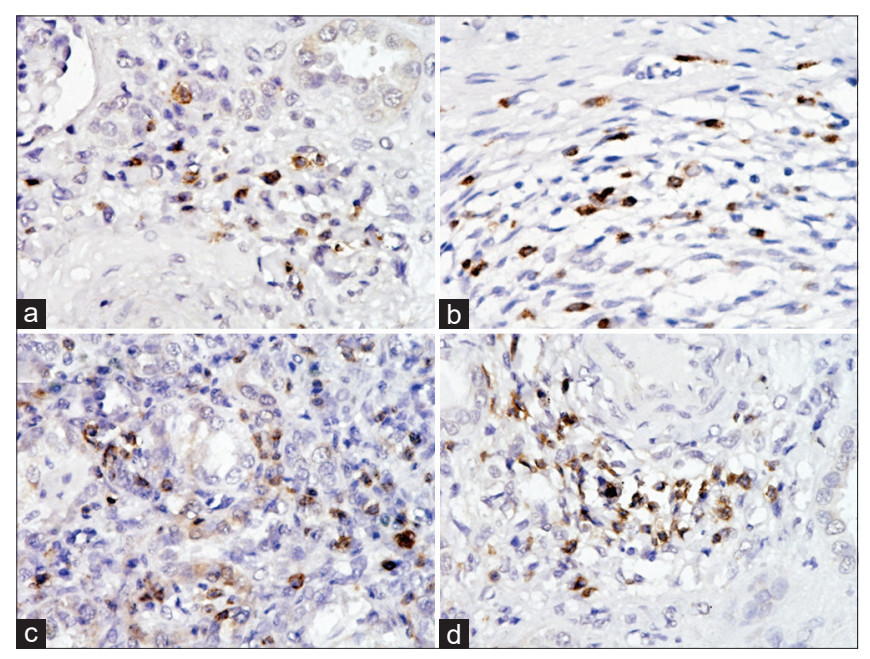

Figure 1: (a) Photomicrograph of CD4 + immunostained cells in tumor tissue; (b) photomicrograph of CD8+ immunostained cells in tumor tissue; (c) photomicrograph of CD4 + immunostained cells in peritumoral tissue; (d) photomicrograph of CD8+ immunostained cells in peritumoral tissue to induce activation of innate immune effectors, which transit from the blood to tissues. If local inflammation is sufficient to activate resident dendritic cells, tumor antigen will be acquired and transported to draining lymph nodes where T-cells activation can occur. If immunosuppressive mediators predominate, local inflammation is prevented, and immune priming does not occur. ${ }^{[15]}$ Tumor cells try to evade the immune defense and proliferate as explained by the immunoediting model of Dunn et al. ${ }^{[16]}$ Based on the tumor and host immune system interaction, the tumor may be obliterated or reach a controlled equilibrium with the host or may escape the host immune system and grow unchecked.

This interaction between the tumor cells and the host immune system can have therapeutic ramifications. The activity of immunosurveillance can be enhanced by certain compounds which can target the immune checkpoints. Nivolumab and pembrolizumab (two anti PD-1 agents), MEDI4736, MPDL3280A, atezolizumab and avelumab (anti PD-L1 agents), and ipilimumab (an anti cytolytic T-lymphocyte-A4 [CTLA4] agent) are currently under clinical evaluation, showing a certain anti-tumor activity with regard to different solid tumors such as renal-cell carcinoma, nonsmall cell lung cancer, and melanoma. ${ }^{[17-19]} \mathrm{CD} 3+, \mathrm{CD} 4+, \mathrm{CD} 8+, \mathrm{CTL}$ line from TIL of WT had been established by Nagai et al. ${ }^{[20]}$ This CTL line possessed HLA-A2402-restricted and tumor-specific cytotoxicity, indicating that there may exist a T-cell-mediated specific immunity at the tumor site of children with WT.

The presence of TILs within the tumor microenvironment is considered to be an indication of the host immune response to tumor antigens. TILs may become a significant prognostic factor in clinical settings, as they could be seen as an attempt of the immune system to eradicate the neoplasm. TILs infiltration has been reported in various cancers such

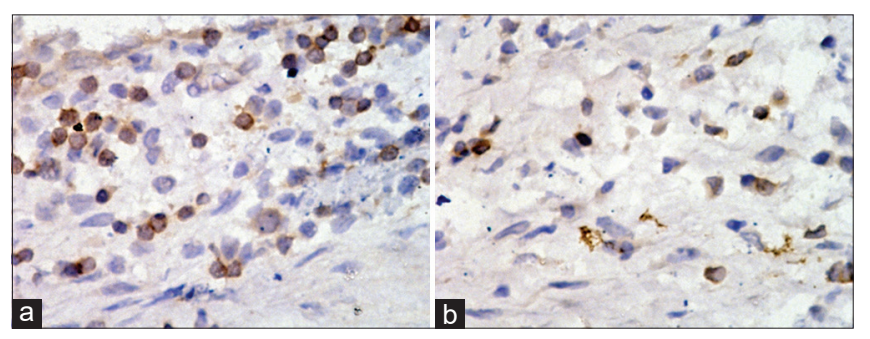

Figure 2: Photomicrographs of immunostained tumor tissue in the child with poor prognosis. (a) CD4 immunostained cells; (b) CD8 immunostained cells

Table 3: Tumor-infiltrating lymphocytes as detected by various markers in the tumoral and peritumoral area in chemotherapy-naive children and children who received preoperative chemotherapy

\begin{tabular}{|c|c|c|c|c|c|c|c|c|}
\hline \multirow[t]{2}{*}{ Group } & \multicolumn{4}{|c|}{ Mean central tumoral area infiltration (\%) } & \multicolumn{4}{|c|}{ Peritumoral area infiltration $(\%)$} \\
\hline & CD3+ & CD4+ & CD8+ & $\mathrm{CD4+/CD8+}$ & CD3+ & CD4+ & CD8+ & CD4+/CD8+ \\
\hline Chemotherapy $(n=17)$ & 20.9 & 11.8 & 7.1 & 0.69 & 22.6 & 13.1 & 6.4 & 2.09 \\
\hline No chemotherapy $(n=8)$ & 21.4 & 12.1 & 7.7 & 0.87 & 22.6 & 12.6 & 7.2 & 1.8 \\
\hline$P$ & 0.35 & 0.43 & 0.17 & 0.31 & 0.5 & 0.69 & 0.08 & 0.89 \\
\hline
\end{tabular}


as breast cancer, ${ }^{[3]}$ ovarian cancer, ${ }^{[4,5]}$ colorectal cancer, ${ }^{[6]}$ hepatocellular carcinoma, ${ }^{[7]}$ lung cancer, ${ }^{[8,9]}$ renal cell carcinoma, ${ }^{[10]}$ melanoma, ${ }^{[11]}$ and gastric cance ${ }^{[12]}$ and has been associated with good prognosis. A systematic review and meta-analysis by Mao et al., ${ }^{[3]}$ Yu et al., ${ }^{[4]}$ showed that infiltration of TILs subsets, CD8+ lymphocytes were associated with improved disease-free survival (DFS) in breast cancer. In ovarian cancer, intraepithelial CD3+ and CD8+ infiltration was associated with increased disease-free survival and overall survival. ${ }^{[5]}$ In renal cell carcinoma, high infiltration of CD8+ cells was associated with good prognosis. ${ }^{[10]}$ Although TILs have been studied in pediatric solid tumors such as neuroblastoma and sarcomas, ${ }^{[13,14]}$ the relevant information in WT is lacking. Moreover, the surgical specimen of this tumor is more readily available as compared to other pediatric solid tumors. These two factors encouraged us to perform this pilot study in children with WT.

The significantly increased TIL (CD3+) in the tumor tissues in this study may denote selective accumulation of TIL within the tumor tissue. This may be attributed to certain chemotactic factors elaborated by the tumor cells or body's reaction to the tumor cells, which it may be sensing as different from self. In the present study, the $\mathrm{CD} 4+/ \mathrm{CD} 8+$ ratio in the peritumoral tissue is about 2 , which is the normal ratio seen in the blood. The $\mathrm{CD} 4+/ \mathrm{CD} 8+$ ratio is reversed in the tumor tissue (mean of 0.74 and median of 0.58 ), and this is because of the selective infiltration of CD8+ cells into the tumor. The two patients who died in this study have been unable to mount an effective immune response to the tumor, as evidenced by the low CD3 + cells count of $16 \%$ and $14.6 \%$ as compared to a mean of $21.72 \% \pm 1.54 \%$ in the patients who survived [Table 1]. Besides the overall low $\mathrm{CD} 3+$ counts, the $\mathrm{CD} 8+$ counts in the tumor tissue have been even lower ( $4 \%$ and $3.6 \%$ ) as compared to a mean of $12.83 \% \pm 1.9 \%$ in patients who survived [Table 1]. Clearly, in both these patients, the reversal of $\mathrm{CD} 4+/ \mathrm{CD} 8+$ ratio was not seen. The $\mathrm{CD} 4+/ \mathrm{CD} 8+$ ratio in these two patients, who died, was 2.62 and 2.72 as compared to a mean ratio of $0.57 \pm 0.15$ in patients who survived. This indicates that the $\mathrm{CD} 4+/ \mathrm{CD} 8+$ ratio may be a predictor of outcome, as shown in other studies, ${ }^{[21]}$ and needs further evaluation in studies with a large number of patients. Although the study shows the proportion of T-cell infiltration in patients with WT and a possible relationship with prognosis, a definite comment cannot be made due to the small number of patients. Another shortcoming of this study is that only the percentage of the TILs was mentioned rather than the number of TILs per unit tumor cell area.

\section{Conclusion}

To conclude, significant $T$ cells infiltration of the tumor takes place in patients of WT and most of the patients demonstrate a very high concentration of
CD8+ cells (CTLs) in the tumor tissue as compared to the peritumor tissue.

\section{Financial support and sponsorship}

Nil.

\section{Conflicts of interest}

There are no conflicts of interest.

\section{References}

1. Kreider JW, Bartlett GL, Butkiewicz BL. Relationship of tumor leucocytic infiltration to host defense mechanisms and prognosis. Cancer Metastasis Rev 1984;3:53-74.

2. Gubin MM, Zhang X, Schuster H, Caron E, Ward JP, Noguchi T, et al. Checkpoint blockade cancer immunotherapy targets tumour-specific mutant antigens. Nature 2014;515:577-81.

3. Mao Y, Qu Q, Chen X, Huang O, Wu J, Shen K. The prognostic value of tumor-infiltrating lymphocytes in breast cancer: A systematic review and meta-analysis. PLoS One 2016;11:e0152500.

4. Yu X, Zhang Z, Wang Z, Wu P, Qiu F, Huang J. Prognostic and predictive value of tumor-infiltrating lymphocytes in breast cancer: A systematic review and meta-analysis. Clin Transl Oncol 2016;18:497-506.

5. Li J, Wang J, Chen R, Bai Y, Lu X. The prognostic value of tumor-infiltrating $\mathrm{T}$ lymphocytes in ovarian cancer. Oncotarget 2017;8:15621-31.

6. Deschoolmeester V, Baay M, Van Marck E, Weyler J, Vermeulen P, Lardon F, et al. Tumor infiltrating lymphocytes: An intriguing player in the survival of colorectal cancer patients. BMC Immunol 2010;11:19.

7. Yao W, He JC, Yang Y, Wang JM, Qian YW, Yang T, et al. The prognostic value of tumor-infiltrating lymphocytes in hepatocellular carcinoma: A systematic review and meta-analysis. Sci Rep 2017;7:7525.

8. Liu H, Zhang $\mathrm{T}$, Ye J, Li H, Huang J, Li X, et al. Tumor-infiltrating lymphocytes predict response to chemotherapy in patients with advance non-small cell lung cancer. Cancer Immunol Immunother 2012;61:1849-56.

9. Geng Y, Shao Y, He W, Hu W, Xu Y, Chen J, et al. Prognostic role of tumor-infiltrating lymphocytes in lung cancer: A meta-analysis. Cell Physiol Biochem 2015;37:1560-71.

10. Baine MK, Turcu G, Zito CR, Adeniran AJ, Camp RL, Chen L, et al. Characterization of tumor infiltrating lymphocytes in paired primary and metastatic renal cell carcinoma specimens. Oncotarget 2015;6:24990-5002.

11. Lee N, Zakka LR, Mihm MC Jr., Schatton T. Tumour-infiltrating lymphocytes in melanoma prognosis and cancer immunotherapy. Pathology 2016;48:177-87.

12. Kim KJ, Lee KS, Cho HJ, Kim YH, Yang HK, Kim WH, et al. Prognostic implications of tumor-infiltrating FoxP3+ regulatory $\mathrm{T}$ cells and $\mathrm{CD} 8+$ cytotoxic $\mathrm{T}$ cells in microsatellite-unstable gastric cancers. Hum Pathol 2014;45:285-93.

13. Mina M, Boldrini R, Citti A, Romania P, D'Alicandro V, De Ioris $\mathrm{M}$, et al. Tumor-infiltrating $\mathrm{T}$ lymphocytes improve clinical outcome of therapy-resistant neuroblastoma. Oncoimmunology 2015;4:e1019981.

14. Mochizuki K, Kawana S, Yamada S, Muramatsu M, Sano H, Kobayashi S, et al. Various checkpoint molecules, and tumor-infiltrating lymphocytes in common pediatric solid tumors: Possibilities for novel immunotherapy. Pediatr Hematol Oncol 2019;36:17-27. 
15. Liotta LA, Kohn EC. The microenvironment of the tumour-host interface. Nature 2001;411:375-9.

16. Dunn GP, Old LJ, Schreiber RD. The immunobiology of cancer immunosurveillance and immunoediting. Immunity 2004;21:137-48.

17. Ravelli A, Reuben JM, Lanza F, Anfossi S, Cappelletti MR, Zanotti L, et al. Immune-related strategies driving immunotherapy in breast cancer treatment: A real clinical opportunity. Expert Rev Anticancer Ther 2015;15:689-702.

18. Vesely MD, Schreiber RD. Cancer immunoediting: Antigens, mechanisms, and implications to cancer immunotherapy. Ann $\mathrm{N}$ Y Acad Sci 2013;1284:1-5.
19. Qin A, Coffey DG, Warren EH, Ramnath N. Mechanisms of immune evasion and current status of checkpoint inhibitors in non-small cell lung cancer. Cancer Med 2016;5:2567-78.

20. Nagai K, Yamada A, Eguchi $H$, Kato $H$, Itoh $K$. HLA-A2402-restricted and tumor-specific cytotoxic $T$ lymphocytes from tumor-infiltrating lymphocytes of a child with Wilms' tumor. Pediatr Res 1997;42:122-7.

21. Sato E, Olson SH, Ahn J, Bundy B, Nishikawa H, Qian F, et al. Intraepithelial CD8+tumor-infiltrating lymphocytes and a high $\mathrm{CD} 8+/$ regulatory $\mathrm{T}$ cell ratio are associated with favorable prognosis in ovarian cancer. Proc Natl Acad Sci U S A 2005; 102:18538-43. 